\title{
Histochemistry of glycoconjugates in mucous cells of Salmo trutta uninfected and naturally parasitized with intestinal helminths
}

\author{
G. Bosi, S. Arrighi, A. Di Giancamillo, C. Domeneghini* \\ Department of Veterinary Sciences and Technologies for Food Safety, Faculty of Veterinary Medicine, University of Milan, \\ Via Trentacoste n. 2, 20134 Milan, Italy
}

\begin{abstract}
Mucus secreted onto the surface of the intestine forms a physical barrier to invading parasites so that a possible attachment of helminths to the surface is prevented and their expulsion by peristalsis facilitated. In mammals, intestinal parasites induce hyperplasia and hypertrophy of intestine goblet cells and provoke changes in the mucus composition. In fish, this topic has received less attention. In the present investigation, histochemical methods were employed to compose intestinal mucous cell numbers and their glycoconjugate composition were compared by uninfected brown trout Salmo trutta and in S. trutta parasitized with Cyathocephalus truncatus or Pomphorhynchus laevis. When $P$. laevis was present in the intestine of the brown trout, the total mucous cell number, and the number of mucous cells containing acid or mixed glycoconjugates were significantly enhanced. No significant change in the total mucous cell number was detected in the intestine of fish parasitized with $C$. truncatus in comparison with uninfected brown trout. A significant increase was observed in the number of both acid (especially sulphated) and mixed glycoconjugates containing mucous cells as well as a significant decrease in the number of neutral glycoconjugates containing mucous cells. When intestinal helminths were present, the thickness of the adherent mucous gel increased. In a limited number of other fish species, the occurrence of gill and intestinal parasites has been reported to increase the mucosal glycoconjugate secretions. Our study is the first quantitative report on the effects of intestinal helminths on the density of mucous cells and mucus composition in a fish species.
\end{abstract}

KEY WORDS: Glycoconjugates · Mucus composition · Mucous cell number · Intestinal parasites · Brown trout

Resale or republication not permitted without written consent of the publisher

\section{INTRODUCTION}

The infection of the mammalian intestine with parasites results in a blood flow congestion of intestinal mucosa, goblet cell hyperplasia and hypertrophy and consequent enhanced mucus secretion (Miller 1987, Fairweather 1997, Marzouk et al. 2002). An increase in the proportion of intestinal goblet cells has been described, among other cases, in lambs experimentally parasitized with Nematodirus sp. (Usenov 1981), in intestinal villi during the immune cell-mediated expulsion of Nyppostrongilus brasiliensis from the rat intestine (Miller \& Nawa 1979, Miller et al. 1981,
Miller \& Huntley 1982, Miller 1987), in the stomach and small intestine of rats infected with Taenia taeniaeformis (Cook \& Williams 1981), and in mice small intestine parasitized with Hymenolepis diminuta (McKay et al. 1990) and Trichinella spiralis (Kahn et al. 2001). Qualitative changes in goblet cell secretions have also been described in response to the presence of parasites (Konink et al. 1988, Ishikawa et al. 1993, Fairweather 1997, Manjili et al. 1998), and it has been suggested that an increased secretion of chemically different mucus contributes to the elimination of parasites from the alimentary tract (Ishikawa et al. 1993, Miller 1987). 
Compared with mammals, less is known about the effects induced by intestinal parasites upon the intestinal mucous secretions in fish. An excess of mucus has been observed in the intestine of the chub Leuciscus cephalus and the brown trout Salmo trutta, parasitized with Pomphorhynchus laevis (Acanthocephala) (Dezfuli et al. 2002a,b), in the intestine of the cobia Rachycentron canadum infected with Serrasentis nadakali (Acanthocephala) (George \& Nadakal 1978), as well as in the intestines of the bluegill Lepomis macrochirus and green sunfish L. Cyanellus parasitized with Neoechinorhynchus cylindratus (Acanthocephala) (AdelMeguid et al. 1995). These studies only provided a description of the altered intestinal structural aspects, whereas no attention was paid to an objective quantification of possible cell hyperplasia (or depletion) and the chemical composition of the mucous cells.

On the other hand, a specific consideration of the possible quantitative and qualitative changes induced in intestinal mucous cells by the presence of parasites is remarkably interesting from the point of view of fish host-parasite interactions. Buchmann \& Bresciani (1998) showed that monogeneans seem to 'select' the sites of attachment to the rainbow trout skin, the choice of appropriate localizations depending on both mechanical and chemical stimuli. In particular, the site selection by either intestinal or external parasites (Schabuss et al. 1997, Buchmann \& Lindenstrom 2002) appears strongly influenced by the chemical coding of mucous cells (either intestine- or skin-localized), whose secreted complex glycoproteins constitute an articulate and dynamic microenvironment. In addition, it appears not devoid of interest that mucous cells of some fish species appear able to synthesize and discharge defensive substances (Smith et al. 2000, Nakamura et al. 2001, Cho et al. 2002), and in this respect it may also be useful to know the morpho-functional variations induced by parasites on fish intestinal mucous cells.

The present paper provides for the first time in a fish species a comparison between the number of intestinal mucous cells in uninfected Salmo trutta and a cospecific parasitized with Cyathocephalus truncatus (Cestoda) or Pomphorhnchus laevis (Acanthocephala). Moreover, this study represents the first report on the chemical contents of the different mucous cell populations which are quantified comparatively, both in the absence and in the presence of the cestode and acanthocephalan within the brown trout intestine.

\section{MATERIALS AND METHODS}

Fifty-six specimens of Salmo trutta (total length 10 to $48 \mathrm{~cm}$ ) were sampled by electrofishing in channels and tributaries of the River Brenta, north of Padua, Italy.
The specimens of brown trout were anesthetized with $8 \% \beta, \beta, \beta$-trichlorotetrabutyl alcohol and then dissected, after opening the abdominal cavity. Twentyone brown trout were uninfected, the remaining ( $\mathrm{n}=$ 35) were infected with either the acanthocephalan Pomphorhynchus laevis (15 individuals) or with the cestode Cyathocephalus truncatus (20 individuals). The densities of parasite were: 1 to 95 P. laevis per host; 1 to 82 C. truncatus per fish. Small pieces of the proximal intestine from both uninfected and infected fish were excised, fixed in Bouin's fluid for $8 \mathrm{~h}$, dehydrated to a graded series of ethanol, cleared in xylene, and embedded in paraffin. The small pieces of parasitized fish were in close vicinity to the opening of pyloric caeca, at a maximum distance of $1 \mathrm{~cm}$ from them. The small pieces from uninfected fish were excised from exactly the same intestinal region.

For qualitative histochemical studies, sections (6 $\mu \mathrm{m}$ thick) of the proximal intestine of both uninfected and parasitized Salmo trutta were stained with Alcian Blue 8GX pH 2.5/periodic acid-Schiff (AB/PAS) sequence (Mowry 1963) and High Iron Diamine/Alcian Blue 8GX pH 2.5 (HID/AB) reaction (Reid et al. 1989, Spicer 1965). The AB/PAS method was chosen so as to demonstrate both acidic glyconjugates (blue-stained) and periodate reactive vicinal diols (purple-stained), as well as mixtures of the former and the latter (violet-stained). The HID/AB sequence was used to differentiate sulphated (brownish-black-stained) from carboxylated, non-sulphated (blue-stained) acidic glycoconjugates.

For quantitative histochemical studies, we analysed 2 sections of the proximal intestine from either 10 specimens of uninfected brown trout, or 10 Salmo trutta parasitized with the acanthocephalan, or 10 fish infected with the cestode. In the sections stained with the $\mathrm{AB} / \mathrm{PAS}$ reaction, intestinal mucous cells were counted at the level of 4 intestinal folds. We distinguished among those containing acid (blue-stained, AB), neutral (purple-stained, PAS), as well as mixed (acid and neutral) glycoconjugates (violet-stained, AB/PAS). In the sections stained with the HID/AB sequence, the mucous cells containing sulphated glycoconjugates (brownish-black, HID) were counted at the level of the 4 intestinal folds.

The thickness of the adherent mucous gel was measured utilizing the AB/PAS stained sections from 10 non-parasitized brown trout, as well as of 10 trout infected with Pomphorhynchus laevis and 10 fish parasitized with Cyathocephalus truncatus (see above), and reported as mean \pm standard error of the mean. This latter parameter was obtained by measuring the adherent mucous gel at 10 randomly selected points in each section.

Sections were observed and photographed under an Olympus BX50 photomicroscope (Olympus), equipped 
with a digital camera and DP software (Olympus) for the image analysis. Measures of adherent mucous gel thickness were made at $400 \times$, and counts of mucous cell number were made at $100 \times$ utilizing the DP software.

The quantitative data were reported as mean number of mucous cell per intestinal fold ( \pm standard error of the mean), and analysed by 1-way ANOVA (Table 1) using the General Linear Models procedure of the SAS Institute (1985). The level of significance was set at $p=0.05$.

\section{RESULTS}

Parasitological data on the presence of Pomphorhynchus laevis and Cyathocephalus truncatus in the intestine of Salmo trutta, as well as values of the intensity of infection for each parasite were reported in a previous study of ours on the same fishes (Dezfuli et al. 2003).

In the proximal intestine of uninfected Salmo trutta, mucous cells contained predominantly periodic acidSchiff-stained, neutral glycoconjugates (PAS) (Table 1, Fig. 1a). Brownish-stained, High Iron Diamine (HID)positive mucous cells were considerably less numerous than the blue-stained, sialylated glycoconjugates containing mucous cells (Table 1). The adherent mucous gel (Fig. 1a) was $5.49 \pm 0.52 \mathrm{~mm}$ thick.

When the acanthocephalan Pomphorhnchus laevis was present in the proximal intestine of the brown trout, the total mucous cell number was increased (Table 1, Fig. 1b) in comparison with uninfected fish (Fig. 1a), as well as in comparison with the brown trout parasitized with the cestode Cyathocephalus truncatus (Fig. 1c), and the differences were in both cases statistically significant (Table 1). Either mucous cells containing acid glycoconjugates (AB) or mucous cells con-

Table 1. Salmo trutta. Mean number \pm mean standard error of mucous cells per intestinal fold in uninfected brown trout compared with trout parasitized with Pomphorhynchus laevis (Acanthocepahala) and Cyathocephalus truncatus (Cestoda). Mucous cells were counted for their staining affinity to Alcian Blue (AB) and/or to periodic acid-Schiff (PAS), and to High Iron Diamine (HID). Counts and statistical 1-way ANOVA were performed as reported in the text. $F=$ parameter of the 1-way ANOVA

\begin{tabular}{|c|c|c|c|c|c|}
\hline \multirow{2}{*}{$\begin{array}{l}\text { Mucous cells } \\
\text { positive to: }\end{array}$} & \multirow[t]{2}{*}{ Uninfected } & \multicolumn{2}{|c|}{ Parasitized with } & \multirow[t]{2}{*}{$F$} & \multirow[t]{2}{*}{$\mathrm{p}$} \\
\hline & & P. laevis & C. truncatus & & \\
\hline $\mathrm{AB}$ & $20.13^{\mathrm{a}} \pm 2.01$ & $38.25^{\mathrm{b}} \pm 7.25$ & $43.20^{b} \pm 6.88$ & 4.26 & $<0.05$ \\
\hline PAS & $33.87^{\mathrm{A}} \pm 2.46$ & $50.63^{\mathrm{A}} \pm 10.59$ & $10.00^{\mathrm{B}} \pm 2.18$ & 10.17 & $<0.001$ \\
\hline $\mathrm{AB} / \mathrm{PAS}$ & $10.07^{a} \pm 0.88$ & $21.00^{\mathrm{b}} \pm 3.23$ & $16.50^{\mathrm{b}} \pm 1.81$ & 6.25 & $<0.05$ \\
\hline HID & $0.16^{\mathrm{A}} \pm 0.03$ & $0.03^{\mathrm{A}} \pm 0.18$ & $1.07^{\mathrm{B}} \pm 0.25$ & 10.06 & $<0.001$ \\
\hline \multicolumn{3}{|c|}{ mucous cells } & $69.70^{a} \pm 7.65$ & 6.88 & $<0.05$ \\
\hline $\begin{array}{l}\mathrm{A}, \mathrm{B}=\text { differen } \\
\mathrm{a}, \mathrm{b}=\text { differen }\end{array}$ & $\begin{array}{l}\text { at letters indica } \\
\text { t letters indica }\end{array}$ & $\begin{array}{l}\mathrm{p}<0.001 \\
\mathrm{p}<0.05\end{array}$ & & & \\
\hline
\end{tabular}

taining mixed (acid and neutral) glycoconjugates (AB/PAS) were significantly enhanced in number (Table 1). However, no statistical difference, as compared with uninfected fish (Fig. 1d), was observed in the number of intestinal mucous cells containing sulphated glycoconjugates (HID) (Table 1, Fig. 1e). The adherent mucous gel was significantly thicker (12.09 \pm $0.68 \mathrm{~mm})(t$-value $=-7.710, \mathrm{p}<0.001$ vs uninfected fish) when $P$. laevis was present in the brown trout intestine (Fig. 1b).

No significant change in the total mucous cell number was detected in the intestine of fish parasitized with Cyathocephalus truncatus in comparison with uninfected brown trout (Table 1). Nevertheless, a significant increase was observed in the number of both acid (AB) and mixed (acid and neutral, AB/PAS) glycoconjugates containing mucous cell number, as well as a significant decrease in the number of neutral glycoconjugates (PAS) containing mucous cell number (Table 1, Fig. 1c). The number of mucous cells containing sulphated glycoconjugates (HID) significantly increased in the brown trout parasitized with C. truncatus in comparison with uninfected fish (Table 1, Fig. 1f). The thickness of the adherent mucous gel was $11.31 \pm 0.61 \mathrm{~mm}(t$-value $=-7.261, \mathrm{p}<0.001$ vs uninfected fish) when the cestode was present in the proximal intestine of Salmo trutta (Fig. 1c).

\section{DISCUSSION}

In this paper we have for the first time clearly demonstrated that in the intestine of the brown trout the acanthocephalan Pomphorhynchus laevis induced a dramatic increase of total mucous cell number whereas Cyathocephalus truncatus had no significant effect. When the cestode was present, a strong reduction in the number of mucous cells containing neutral mucosubstances occurred. The number of sulphated glycoconjugates containing intestinal mucous cells was higher in both the brown trout infected with $C$. truncatus and in the brown trout parasitized with $P$. laevis than it was in uninfected fish. Both intestinal helminths provoked an increase of the adherent mucous gel thickness.

Intestinal mucus is a high molecular weight glycoprotein synthesized by specialized intestinal epithelial cells. Once secreted, it covers the intestinal mucosa with a continuous adherent semisolid gel, which provides a diffusion barrier for certain low molecular 
weight solutes, and a physical barrier for microrganisms, parasites and their toxins (Lamont 1992, Atuma et al. 2001, Strugala et al. 2003). Qualitative and quantitative changes have been described in some cases as a response to the presence of invading organisms, possibly with a defensive significance. In mammals, hyperplasic and hypertrophic intestinal mucous cells have been observed in response to a variety of helminth infections (Fairweather 1997, Marzouk et al. 2002). Manjili et al. (1998) showed that hyperplasic goblet cell and changes in the composition of goblet cell mucins follow primary infection of guinea pigs with Trichostrongylus colubriformis. In fish, an excess of secreted mucus is generally described when both intestinal and gill epithelia interact with microrganisms (Ferguson et al. 1992, Guzman-Murillo et al. 2000, Lodemel et al. 2001, Kruatrachue et al. 2003), and with intestinal helminths (George \& Nadakal 1978, AdelMeguid et al. 1995).

None of these studies can be considered fully exhaustive because they did not report any objective data about mucous cell numbers or possible different composition of the mucous cell glycoconjugates in the intestine of infected fish.

In this study we observed a significant increase in the number of intestinal mucous cells in Salmo trutta parasitized with Pomphorhnchus laevis in comparison with uninfected individuals. In fact, $P$. laevis penetrated deeply into the intestinal wall of the brown trout and appeared to change the sites of attachment frequently (Dezfuli et al. 2002b). This was likely very detrimental for the intestinal wall and elicited a strong response, in particular at the level of intestinal mucous cells. Moreover, when the acanthocephalan was present in the intestine of the brown trout, a high density of mucous cells containing mixed and acid glycoconjugates was observed, and it is known that acidic glycoconjugates are more defensive than neutral ones towards intestinal lumen contents (Smith 1989, Do- meneghini et al. 1998). A decreased number of mucous cells containing sulphated components was also revealed in the parasitized $S$. trutta.

In Nyppostrongilus brasiliensis-infected rats, Konink et al. (1988) demonstrated a switch from neutral to acidic mucins, with sulphomucins predominating within acid glycoconjugates. Usenov (1981) showed that during larval migration the amount of acid mucopolysaccharides increased in lambs infected with Nematodirus sp. Sialic acid-rich glycoproteins such as orosomucoid, fetuin and mucin could inhibit bacterial adhesion to fish cells (Guzman-Murillo et al. 2000).

In contrast to Pomphorhynchus laevis, the occurrence of Cyathocephalus truncatus in the proximal intestine of the brown trout did not change the total mucous cell number in comparison with uninfected Salmo trutta. This was probably due to the fact that the cestode did not cause the severe damage to the host intestinal wall induced by the acanthocephalan. Nevertheless, the cestode provoked an increased mucous cell number containing mixed and acid glycoconjugates, with a higher number of sulphated glycoconjugates containing mucous cells than in uninfected brown trout or in individuals parasitized with P. laevis. Moreover, a low number of neutral glycoconjugates containing cells was observed in $S$. trutta parasitized with $C$. truncatus. Sulphated glycoconjugates are known to confer a high density to mucous secretions, thus possibly enabling them to trap invading organisms (Tibbets 1997). More specifically, changes in the composition of mucus in parasitized fish could be related to synthesis of molecules involved in the mechanism of 'exclusion' of the parasites from their preferred site in the gut (Miller 1987, 1996). For example, pufflectin is the first fish mucosal glycoconjugate produced in gills, skin and intestine of Fugu rubripes that has recently been demonstrated to bind to parasitic metazoans (Tsutsui et al. 2003).

Fig. 1. Salmo trutta. Proximal intestine. (a) Uninfected fish Alcian Blue (AB)/periodic acid-Schiff (PAS) reaction. In the intestinal folds, several mucous cells are seen. The majority of these are PAS-reactive (thick arrows, purple-stained), a small number of them are AB-reactive (thin arrows, blue-stained). The adherent mucous gel (arrowheads) is similarly prevalently PAS-reactive. $\mathrm{tm}=$ tunica muscularis. Scale bar $=200 \mu \mathrm{m}$. (b) Pomphorhynchus laevis infecting $S$. trutta AB/PAS reaction. In the intestinal folds, several mucous cells are seen. The majority of these are AB-reactive (thin arrows, blue-stained), a small number of them are PASreactive (thick arrows, purple-stained). The adherent mucous gel (arrowheads) is similarly prevalently AB-reactive. In the lumen, a section of 1 acanthocephalan (A) is evident. $\mathrm{sc}=$ stratum compactum, sg $=$ stratum granulosum. Scale bar $=200 \mu \mathrm{m}$. (c) Cyathocephalus truncatus infecting fish AB/PAS reaction. In the intestinal folds, several mucous cells are seen. The majority of these are AB/PAS-reactive (thin arrows, violet-stained), a small number of them are PAS-reactive (thick arrow, purple-stained). The adherent mucous gel (arrowheads) is similarly prevalently AB/PAS-reactive. In the lumen, a section of 1 cestode (C) is evident. Scale bar $=200 \mu \mathrm{m}$. (d) Uninfected fish, High Iron Diamine (HID)/AB reaction. In intestinal folds, here transversally sectioned, a large number of mucous cells are AB-reactive (thick arrows, blue-stained), rare mucous cells are HID-reactive (thin arrows, brownishstained). Scale bar $=50 \mu \mathrm{m}$. (e) P. laevis infected fish HID/AB reaction. The intestinal folds contain a large number of mucous cells, which are AB-reactive (thick arrows, blue-stained), rare mucous cells are HID-reactive (thin arrow, brownish-stained). A = section of 1 acanthocephalan. Scale bar $=100 \mu \mathrm{m}$. (f) C. truncatus infected fish HID/AB reaction. Thick arrows show the predominant AB-reactive mucous cells (blue-stained), thin arrows indicate those ones which are HID-reactive (brownish-stained) (arrowheads = adherent mucous gel). Scale bar $=50 \mu \mathrm{m}$ 


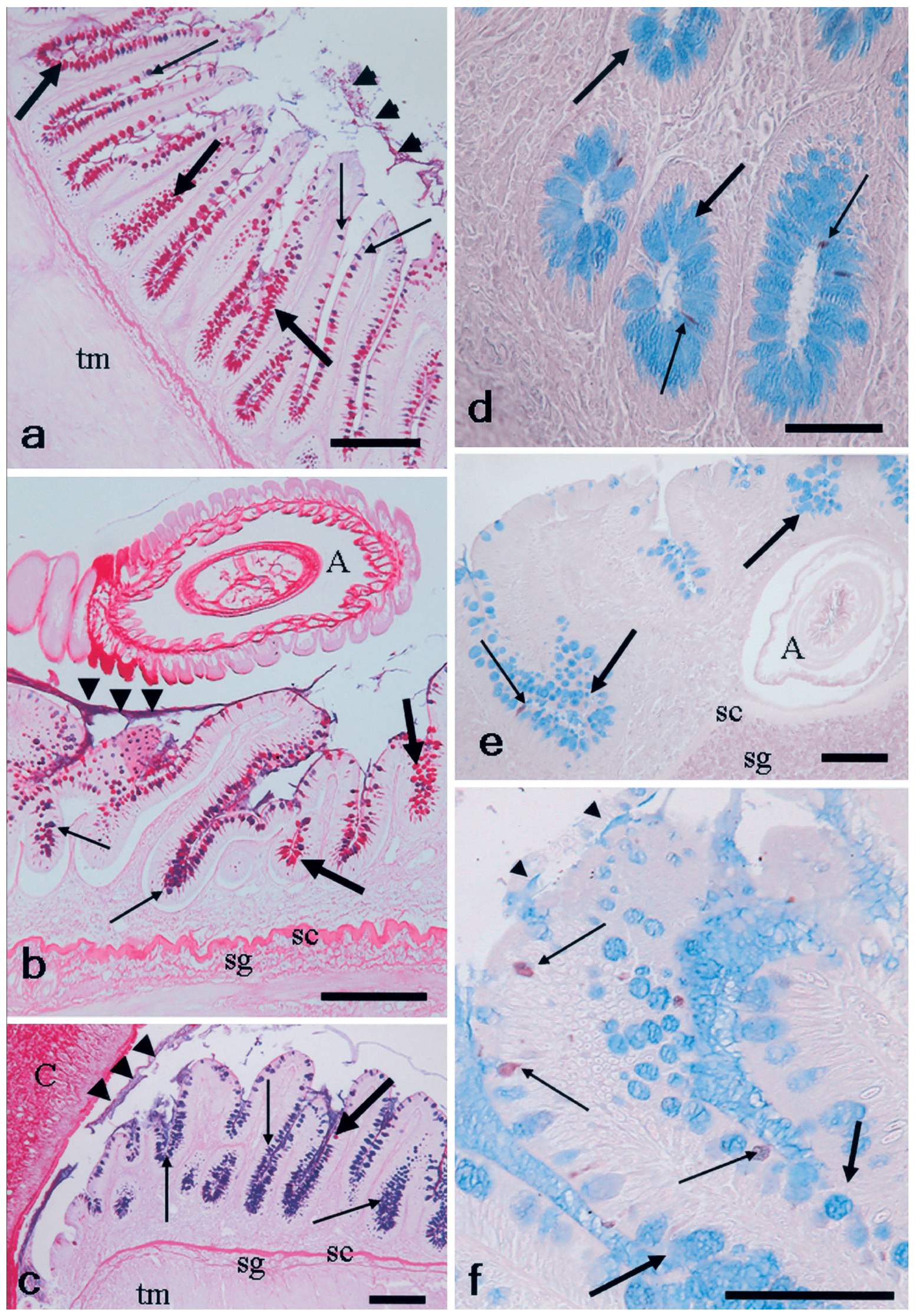


The thickness of adherent mucous gel is significantly higher in the proximal intestine of Salmo trutta infected with helminths than in the uninfected brown trout. The histological technique obviously dehydrated the adherent mucous gel, and consequently, we were not able to obtain absolute measurement values (Matsuo et al. 1997, Atuma et al. 2001). Our aim was, on the other hand, to obtain relative values of thickness for comparative purposes between uninfected and infected fish, and we have really obtained significant relative values because it is conceivable that the amount of dehydration consequent to histological techniques was the same for all the individuals.

Mucus secretion from intestinal goblet cells is stimulated by a number of secretagogues, including acetylcholine from enteric nerves, leukotrienes from inflammatory cells, and prostaglandins (Manjili et al. 1998, Fairweather 1997, Lamont 1992). A variety of peptides may also be involved in the regulation of mucus release during inflammatory states (Lamont 1992, Fairweather 1997). Plaisancié et al. (1998) provided evidence that rat colonic mucin secretion may be induced by several mediators (vasoactive intestinal peptide, bombesin, and serotonin) from the neuroendocrine and immune systems, including a marked increase in the discharge of colonic mucin from the isolated vascularly perfused rat colon (Plaisancié et al. 1998).

Dezfuli et al. $(2000,2002 b, 2003)$ showed that the presence of intestinal helminths in the intestine of the brown trout induced alterations in the occurrence and distribution of the components belonging to the host neuroendocrine system. In the proximal intestine of Salmo trutta parasitized with the cestode Cyathocephalus truncatus, the number of endocrine cells per intestinal fold, which were immunoreactive to the serotonin antiserum, was increased in comparison with uninfected fish (Dezfuli et al. 2000). When Pomphorhynchus laevis was present in the alimentary canal of the brown trout, an increased occurrence of nerve fibres immunoreactive to the bombesin and serotonin antisera was observed in the myenteric plexus (Dezfuli et al. 2002b). Vasoactive intestinal peptide (VIP) was not demonstrated in the neuroendocrine system of uninfected $S$. trutta, but nerve fibres immunoreactive to this neuropeptide were revealed in the myenteric plexus of the brown trout parasitized with $C$. truncatus and P. laevis (Dezfuli et al. 2000, 2002b).

It is conceivable that the intestinal mucous cell hyperplasia and the differences in their glycoconjugate composition in the parasitized brown trout when compared with uninfected fish are to be correlated with the alterations of the neuroendocrine system reported in previous works of ours (Dezfuli et al. 2000, 2002b, 2003), which can thus differently sustain secretory pro- cesses in uninfected vs infected brown trout. These morpho-functional changes seem in turn to be interpreted as the expression of biochemical and physiological alterations caused by intestinal parasites (Castro 1989).

The problem of the possible presence of defensive substances within glycoconjugates of intestinal mucous cells remains at present unsolved, and we plan to carry out a further study aimed at elucidating the question as to whether the qualitative differences evidenced here are possibly linked to the synthesis and secretion of particular defensive molecules.

Acknowledgements. The authors would like to thank Dr. B. S. Dezfuli (Department of Biology, University of Ferrara) for his help in collecting fishes. The excellent technical assistance of Mr Paolo Stortini is gratefully acknowledged. This investigation was in part supported by a FIRST (2002) grant from the University of Milan to C.D.

\section{LITERATURE CITED}

Adel-Meguid M, Esch GW, Eure HE (1995) The distribution and pathobiology of Neoechinorhynchus cylindratus in the intestine of green sunfish, Lepomis cyanellus. Parasitology 111:221-231

Atuma C, Strugala V, Allen A, Holm L (2001) The adherent gastrointestinal mucus gel layer: thickness and physical state in vivo. Am J Physiol 280: G922-G929

Buchmann K, Bresciani J (1998) Microenvironment of Gyrodactylus derjavini on rainbow trout Oncorhynchus mykiss: association between mucous cell density in skin and site selection. Parasitol Res 84:17-24

Buchmann K, Lindenstrom T (2002) Interactions between monogenean parasites and their fish hosts. Int J Parasitol 32:309-319

Castro GA (1989) Immunophysiology of enteric parasitism. Parasitol Today 5:11-19

Cho JK, Park IY, Kim HS, Lee WT, Kim MS, Kim SC (2002) Cathepsin D produces antimicrobial peptide parasin I from histone H2A in the skin mucosa of fish. FASEB J 16:429-431

Cook RW, Williams JF (1981) Pathology of Taenia taeniaeformis infection in the rat: gastrointestinal changes. J Comp Pathol 91:205-216

Dezfuli BS, Arrighi S, Domeneghini C, Bosi G (2000) Immunohistochemical detection of neuromodulators in the intestine of Salmo trutta L. naturally infected with Cyathocephalus truncatus Pallas (Cestoda). J Fish Dis 23:265-273

Dezfuli BS, Giari L, Simoni E, Bosi G, Manera M (2002a) Histopathology, immunohistochemistry and ultrastructure of the intestine of Leuciscus cephalus (L.) naturally infected with Pomphorhynchus laevis (Acanthocephala). J Fish Dis 25:7-14

Dezfuli BS, Pironi F, Giari L, Domeneghini C, Bosi G (2002b) Effect of Pomphorhynchus laevis (Acanthocephala) on putative neuromodulators in the intestine of naturally infected Salmo trutta. Dis Aquat Org 51:27-35

Dezfuli BS, Giari L, Arrighi S, Domeneghini C, Bosi G (2003) Influence of enteric helminths on the distribution of intestinal endocrine cells belonging to the diffuse endocrine system in brown trout, Salmo trutta L. J Fish Dis 26: 155-166

Domeneghini C, Straini Pannelli R, Veggetti A (1998) Gut 
glycoconjuagtes in Sparus aurata L. (Pisces, Teleostei): a comparative histochemical study in larval and adult ages. Histol Histopathol 13:359-372

Fairweather I (1997) Peptides: an emerging force in host response to parasitism. In: Beckage NE (ed) Parasites and pathogens: effects on host hormones and behaviour. Chapman \& Hall, New York, p 113-139

Ferguson HW, Morrison D, Ostland VE, Lumsden J, Bryne P (1992) Responses of mucus-producing cells in gill disease of rainbow trout (Oncorhynchus mykiss). J Comp Pathol 106:255-265

George PV, Nadakal AM (1978) Observations on the intestinal pathology of the marine fish, Rachycentron canadus (Gunther) infected with the acanthocephalid worm, Serrasentis nadakali (George \& Nadakal, 1978). Hydrobiologia 78:59-62

Guzman-Murillo MA, Merino-Contreras ML, Ascencio F (2000) Interaction between Aeromonas veronii and epithelial cells of spotted sand bass (Paralabrax maculatofasciatus) in culture. J Appl Microbiol 88:897-906

Ishikawa N, Horii Y, Nawa Y (1993) Immune-mediated alteration of the terminal sugars of goblet cells mucins in the small intestine of Nippostrongylus brasiliensis-infected rats. Immunology 78:303-307

Kahn WJ, Blennerhasset P, Ma C, Matthaei KI, Collins SM (2001) Stat6 dependent goblet cells hyperplasia during intestinal nematode infection. Parasite Immunol 23:39-42

Konink JFJG, Mirk MH, Hendriks HGCJ, Mouwen JMVM, Van Dijk JE (1988) Nippostrongylus brasiliensis: histochemical changes in the composition of mucins in goblet cells during infection in rats. Exp Parasitol 65:84-90

Kruatrachue M, Rangsayatorn N, Pokethitiyook P, Upatham ES, Singhakaew S (2003) Histopathological changes in the gastrointestinal tract of fish, Puntius gonionotus, fed on dietary cadmium. Bull Environ Contam Toxicol 71:561-569

Lamont JT (1992) Mucus: the front line of intestinal mucosal defense. In: Stead RH, Perdue MH, Cooke H, Powell DW, Barrett KE (eds) Neuro-immuno-physiology of the gastrointestinal mucosa: implications for inflammatory disease. Ann NY Acad Sci 664:190-201

Lodemel JB, Mayhew TM, Myklebust R, Olsen RE, Espelid S, Ringø E (2001) Effect of three dietary oils on disease susceptibility in Arctic charr (Salvelinus alpinus L.) during cohabitant challenge with Aeromonas salmonicida ssp. salmonicida. Aquac Res 32:935-945

Manjili MH, France MP, Sangster NC, Rothwell TLW (1998) Quantitative and qualitative changes in intestinal goblet cells during primary infection of Trichostrongylus colubriformis high and low responder guinea pigs. Int J Parasitol 28:761-765

Marzouk MSM, Ezz El-Din NM, Mohamed ME, Mahmoud AM, Mohamed RS (2002) Epizootiological and pathological investigations on fishes of lake Manzala infested with some gill and intestinal parasites. Egyptian J Agric Res 80: 901-913

Matsuo K, Ota H, Akamatsu T, Sugiyama A, Katsuyama T (1997) Histochemistry of the surface mucous gel layer of the human colon. Gut 40:782-789

McKay DM, Halton DW, McCaigue MD, Johnston CF, Fairweather I, Shaw C (1990) Hymenolepis diminuta: intestinal goblet cell response to infection in C57 mice. Exp

Editorial responsibility: Wolfgang Körting,

Hannover, Germany
Parasitol 71:9-20

Miller HRP (1987) Gastrointestinal mucus, a medium for survival and for elimination of parasitic nematodes and protozoa. Parasitology 94:S77-S100

Miller HRP (1996) Prospects for the immunological control of ruminant gastrointestinal nematodes: natural immunity, can it be hardness? Int J Parasitol 26:801-811

Miller HRP, Huntley JF (1982) Protection against nematodes by intestinal mucus. Adv Exp Med Biol 144:243-245

Miller HRP, Nawa Y (1979) Nippostrongylus brasiliensis: intestinal goblet cells response in adoptively immunized rats. Exp Parasitol 47:81-90

Miller HRP, Huntley JF, Wallace GR (1981) Immune exclusion and mucus trapping during the rapid expulsion of Nippostrongylus brasiliensis from primed rats. Immunology 44:419-429

Mowry RW (1963) Special value of methods that colour both acidic and vicinal hydroxyl groups in the histochemical study of mucins. With revised directions for the colloidal iron stain, the use of Alcian Blue 8GX and their combination with the periodic acid-Schiff reaction. Ann NY Acad Sci 106:402-443

Nakamura O, Watanabe T, Kamiya H, Muramoto K (2001) Galectin containing cells in the skin and mucosal tissues in the Japanes conger eel, Conger myriaster: an immunohistochemical study. Dev Comp Immunol 25: 431-437

Plaisancié P, Barcelo A, Moro F, Claustre J, Chayvialle JA, Cuber JC (1998) Effects of neurotransmitters, gut hormones, and inflammatory mediators on mucus discharge in rat colon. Am J Physiol 275:G1073-G1084

Reid PE, Owen DA, Fletcher K, Rowan RE, Reimer CL, Rouse GJ, Park CM (1989) The histochemical specificity of high iron diamine-Alcian blue. Histochem J 21:501-504

Schabuss M, Konecny R, Belpaire C, Schiemer F (1997) Endoparasitic helmints of the European eel, Anguilla anguilla, from four disconnected meanders from the rivers Leie and Scheldt in western Flanders, Belgium. Folia Parasitol 44: $12-18$

Smith LS (1989) Digestive functions in teleost fishes. In: Halver JE (ed) Fish nutrition. Academic Press, San Diego, p 331-421

Smith VJ, Fernandes JM, Jones SJ, Kemp GD, Tatner MF (2000) Antibacterial proteins in rainbow trout, Oncorhynchus mykiss. Fish Shellfish Immunol 10:243-260

Spicer SS (1965) Diamine methods for differentiating mucosubstances histochemically. J Histochem Cytochem 13: $211-234$

Strugala V, Allen A, Dettmar PW, Pearson JP (2003) Colonic mucin: method of measuring mucus thickness. Proc Nutr Soc $62: 237-243$

Tibbets IR (1997) The distribution and function of mucous cells and their secretions in the alimentary tract of Arrhamphus sclerolepis krefftii. J Fish Biol 50:809-820

Tsutsui S, Tasumi S, Suetake H, Suzuki Y (2003) Lectins homologous to those of monocotyledonous plants in the skin mucus and intestine of Pufferfish, Fugu rubripes. J Biol Chem 278:20882-20889

Usenov AU (1981) Accumulation of mucus and mucopolysaccharides in the intestines of lambs infected with Nematodirus. Izv Akad Nauk Kazakskoi SSR Biol 2:65-67

Submitted: June 30, 2004; Accepted: September 6, 2004 Proofs received from author(s): February 25, 2005 